\title{
OPTIMALISASI PENYEDIAAN DATA SPASIAL RESOLUSI TINGGI DENGAN PEMBANGUNAN IMAGE MAP SERVICE (STUDI KASUS: PERTAMBANGAN DAERAH SUMATERA)
}

\author{
Teguh Hariyanto ${ }^{1}$, Raka Anindito ${ }^{2}$ \\ 1,2Departemen Teknik Geomatika FTSLK-ITS, Kampus ITS Sukolilo, Surabaya, 60111 \\ e-mail : ${ }^{1}$ teguh_hr@geodesy.its.ac.id, ${ }^{2}$ raka.geodesy@gmail.com
}

\begin{abstract}
Abstrak
Minyak bumi merupakan salah satu aspek dari penyumbang pemasukan terbesar di Indonesia. Hal tersebut didasarkan atas peminatan minyak bumi yang dari dalam maupun luar negeri, sehingga pergerakan harga minyak bumi cenderung meningkat. Bedasarkan fakta tersebut, perlu dilakukan eksplorasi dan eksploitasi terhadap minyak bumi secara maksimum dan optimal. Dalam pelaksanaan pengelolaan terhadap minyak bumi untuk memperoleh hasil yang maksimum, monitoring dan evaluasi merupakan proses yang sangat penting dilakukan. Peta dasar dalam bentuk bentuk data raster merupakan bentuk data yang diperlukan untuk melakukan proses tersebut. Dengan didukung oleh kemajuan teknologi saat ini, persebaran data raster guna mendukung aktivitas-aktivitas pemetaan dapat dilakukan dengan menggunakan jaringan internet. Pembangunan Image Map Service yang dilakukan pada penelitian ini adalah dengan membangun sebuah sistem layanan untuk persebaran data raster sebagai peta dasar dengan menggunakan metode tiling. Dengan didukung dengan diterapkannya metode tiling, maka untuk menampilkan data raster tersebut akan semakin cepat karena data raster akan menampilkan gambar bedasarkan potongan tile yang telah dibentuk pada setiap tingkat zoomingnya. Pada pengimplementasian dari pembuatan Image Map Service yang akan digunakan ini dapat dilakukan persebaran data raster secara online, sehingga mempermudah dalam proses monitoring dan evaluasi. Image Map Service ini juga di dukung dengan ditambahkannya informasi terkait lokasi dari citra tersebut.
\end{abstract}

Kata Kunci: Optimalisasi, Image Map Service, Tile

\begin{abstract}
Petroleum is one aspect of the biggest revenue contributor in Indonesia. This is based on the interest of petroleum from within and outside the country, so that the movement of oil prices tends to increase. Based on this fact, it is necessary to carry out maximum and optimal exploration and exploitation of petroleum. In the implementation of management of petroleum to obtain maximum results, monitoring and evaluation is a very important process carried out. Basic map in the form of raster data is a form of data needed to carry out the process. With the support of current technological advances, the distribution of raster data to support mapping activities can be done using the internet network. The construction of Image Map Service conducted in this research is to build a service system for the distribution of raster data as a base map using the tiling method. Supported by the application of the tiling method, to display the raster data will be faster because the raster data will display images based on pieces of tile that have been formed at each zooming level. In the implementation of making Image Map Service that will be used this can be done raster data distribution online, making it easier in the process of monitoring and evaluation. Image Map Service is also supported by adding information related to the location of the image.
\end{abstract}

Keywords: Optimization, Image Map Service, Tile 


\section{PENDAHULUAN}

\section{Latar Belakang}

Menurut data Bank Indonesia (BI) tahun 2017, minyak bumi tidak hanya merupakan hasil utama usaha pertambangan tetapi juga merupakan bahan ekspor dan salah satu penghasil devisa terbesar. Penggunaan minyak bumi selain sebagai sumber bahan bakar kendaraan pribadi, kebutuhan minyak bumi tersebut datang dari pemakaian dalam industri besar sampai kecil. PT Pertamina EP sebagai salah satu anak dari PT Pertamina (PERSERO) merupakan perusahan yang bergerak dalam bidang produksi serta eksplorasi minyak tersebut. Untuk mendapatkan hasil yang maksimal, diperlukan lah sebuah manajemen dari data-data pendukung baik lapangan maupun non lapangan. Basemap dalam bentuk raster data merupakan sebuah komponen dari data pendukung dalam survei minyak yang dapat digunakan sebagai pembuatan peta tematik maupun untuk pemantauan kondisi lapangan yang ada pada wilayah kerja PT Pertamina EP.

Perkembangan teknologi dewasa ini datang dari berbagai jenis sektor, salah satu perkembangannya adalah dari sektor pemetaan. Persebaran data dalam bentuk data raster guna kebutuhan basemap sebagai pembuatan peta khusus di PT Pertamina EP perlu dilakukan. Karena sistem tersebut dapat memudahkan dan menjadi lebih efektif dalam proses penggunaan data tersebut dibandingkan harus copy data secara manual. Selain itu sifat data yang penting dan rahasia, maka diperlukan sebuah sistem yang dapat mengupdate database dan dapat dibuka oleh seluruh fungsi dari sebuah perusahaan, khususnya pada contoh ini adalah di PT Pertamina EP sekaligus memiliki sifat privacy. Hal yang perlu diperhatikan dalam sistem penyebaran peta ini adalah untuk membuka file yang cukup besar dari segi beban datanya, maka kemampuan dalam menampilkan peta akan semakin lama. Hal tersebut didasarkan pada setiap layer yang ditambahkan di peta di gambarkan secara dinamis artinya, setiap melakukan zoom in atau zoom out peta yang di inginkan, layer tersebut akan digambarkan ulang. Hal ini juga bergantung dari koneksi internet yang digunakan (Esri, 2017).

Maka dari itu pada pembuatan penelitian ini, akan dibuat sebuah Image Map Service, yaitu sebuah layanan untuk melakukan persebaran data dalam bentuk raster dengan menggunakan metode tiling. Sehingga output yang diharapkan dengan terbentuknya sistem Image Map Service ini, akan mempercepat proses penerimaan data dari hardware yang berbeda di seluruh kantor PT Pertamina EP yang membutuhkan data tersebut. Pada pembuatan Image Map Service ini akan dibagi bedasarkan indeks peta skala 1:250.000 dan metode tiling akan membagi data raster tersebut menjadi sebuah potongan kecil di setiap zooming levelnya sehingga dapat mempercepat dalam proses menampilkan data raster tersebut.

\section{Perumusan Masalah}

Adapun perumusan masalah yang akan dibahas pada masalah kali ini adalah:

a. Bagaimana pembuatan Image Map Service untuk menampilkan peta wilayah kerja PT Pertamina EP wilayah kerja sumatera dengan data citra?

b. Bagaimana pembuatan sebuah layanan Image Map Service dengan menggunakan metode tiling?

c. Apakah dampak yang dihasilkan dari pembuatan sistem penyediaan data resolusi tinggi dengan pembangunan Image Map Service?

\section{Batasan Masalah}

Batasan masalah pada penelitian ini adalah sebagai berikut:

a. Data yang digunakan adalah data citra dengan resolusi tinggi dan data citra foto udara dengan wilayah pada wilayah kerja PT. Pertamina EP pertambangan daerah sumatera.

b. Penggunaan citra "esri" wilayah sumatera dengan resolusi menengah dipakai sebagai data dasar untuk proses penampalan citra resolusi tinggi.

c. Hasil dari pembuatan Image Map Service ini digunakan untuk kebutuhan data raster sebagai basemap.

\section{Tujuan Penelitian}

Adapun tujuan dalam penelitian ini adalah sebagai berikut:

a. Mengintegrasikan data raster dengan resolusi tinggi kepada seluruh hardware yang berbeda dengan membangun sistem image map service.

b. Mempermudah dalam proses melakukan pemanggilan atau menampilkan data raster resolusi tinggi 


\section{METODE}

\section{Lokasi Penelitian}

Lokasi penelitian adalah area wilayah kerja PT Pertamina EP wilayah sumatera degan letak astronomis pada $95^{\circ}-105^{\circ}$ Bujur Timur dan $6^{\circ}$ Lintang Utara $-6^{\circ}$ Lintang Selatan yang meliputi:

A. Asset 1
a. Rantau
b. Kuala Simpang Susu
c. Sei lilin
d. Jambi
e. Manduru
f. Suban
g. Garcina Benggala
h. Sungai Gelam

B. Asset 2

Musi

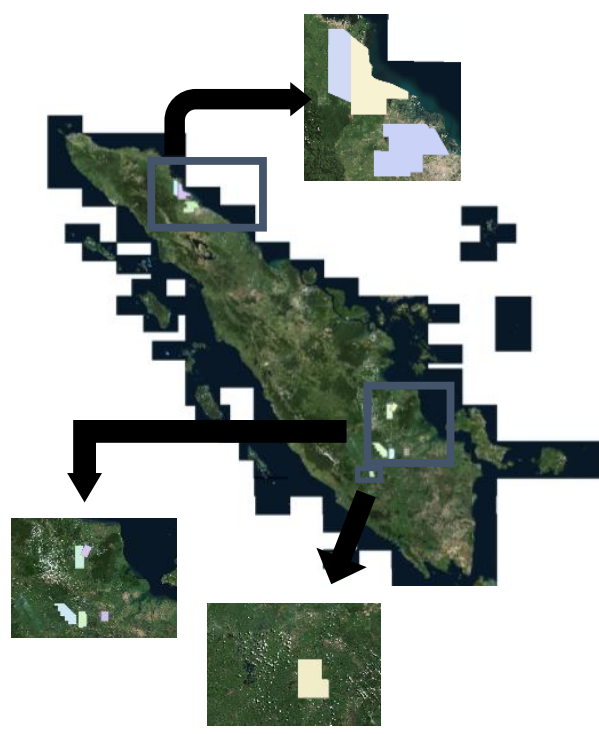

Gambar 1. Wilayah Kerja PT Pertamina EP daerah Sumatera Asset 2

(Sumber : PT Pertamina EP)

\section{Data dan Peralatan}

- Data

Data yang digunakan dalam penelitian ini adalah:
a. Citra World Imagery "esri"
b. Citra Worldview-2 pulau sumatera dengan area wilayah kerja pada:

A. Asset 1

- Rantau

- Kuala Simpang Susu

- Sei lilin

- Manduru
- Suban

- Garcina Benggala

- Sungai Gelam

B. Asset 2

Musi

c. Orthofoto dengan area wilayah kerja pada asset 1 jambi (resolusi spasial: 0.2 m)

d. Indeks peta RBI 1:250.000

- Peralatan

Peralatan yang digunakan dalam penelitian ini adalah:

a. Windows 10

b. Microsoft Office 2016

c. ArcGIS Desktop 10.4

d. ArcGIS Online

\section{Pengolahan Data}

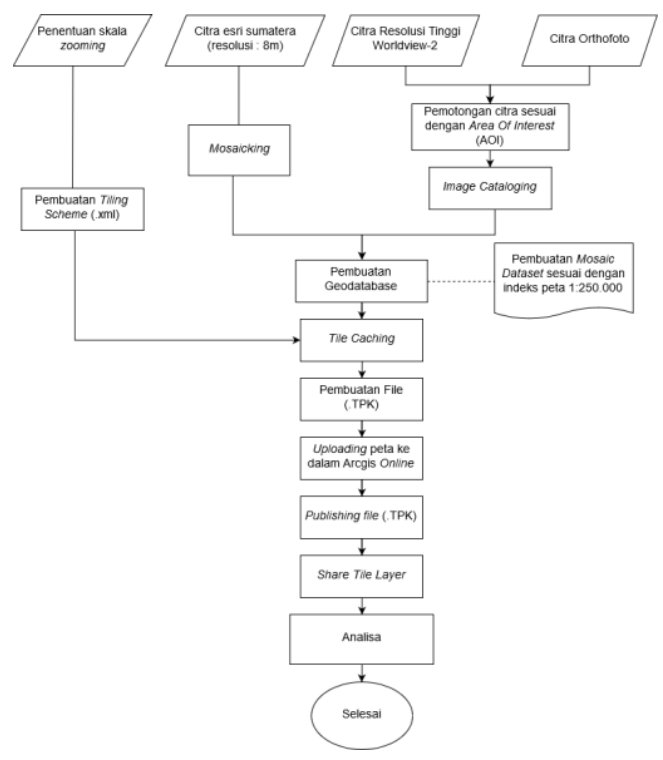

Gambar 1. Diagram Alir Pengolahan Data

Adapun tahapan pengolahan data sebagai berikut:

a. Pemotongan Citra (Cropping)

Pemotongan citra sesuai dengan wilayah Area Of Interest dimaksutkan adalah agar data citra yang diolah nantinya dapat sesusai dengan area wilayah kerja dari PT Pertamina EP. Kemudian cropping citra pada resolusi tinggi berfungsi untuk membagi peta tersebut bedasarkan indeks peta skala 1:250.000.

b. Pembuatan Geodatabase

Pembuatan geodatabase digunakan sebagai tempat untuk melakukan penyimpanan data dalam bentuk raster. Pada penelitia kali ini digunakan file geodatabase karena digunakan 
untuk penyimpanan citra satelit dengan memori yang besar. Pada pembuatan geodatabase ini digunakan mosaic dataset baik untuk raster dengan resolusi menengah maupun tinggi karena selain dapat menggabungkan data citra tersebut, mosaic dataset juga dapat menghapus atau menambahkan data secara parsial. Sehingga, jika publisher akan melakukan updating data dapat menghilangkan serta menambahkan secara parsial.

c. Pembuatan Tiling Scheme

Pembuatan tiling scheme bertujuan untuk membentuk skema zooming pada saat tile caching. Pada penentuan skala zooming digunakan rumus tile scaling system:

Skala $=1:$ (resolusi spasial)* screen dpi/0.0254 meter/inch

d. Tile Caching

Tile Caching merupakan proses dimana dari peta akan dilakukan generalisasi tile yaitu menjadikan peta menjadi potongan kecil per zooming level. Ukuran dari tile pada proses ini menggunakan aturan standard dari penggunaan tile map service yaitu $256 \times 256$ pixel.

e. Pembuatan file (.TPK) dan uploading data Setelah data citra selesai membentuk tile per zooming level, kemudian data tersebut dibentuk dalam file.TPK yang kemudian dalam file .TPK ini data tersebut dapat di lakukan uploading

f. Publishing file (.TPK)

Publishing file memiliki fungsi untuk mengubah file dalam bentuk .TPK sehingga menjadi tile layer pada ArcGIS online.

g. Share Tile Layer

Proses ini merupakan proses dimana publisher akan membagikan data dari image map service yang telah dibuat kepada orang atau instansi yang dapat mengakses data tersebut.

\section{HASIL DAN PEMBAHASAN}

\section{Hasil Pengolahan Citra}

Pembuatan Image Map Service ini digunakan dengan menggunakan platform Arcgis online. Arcgis online sendiri merupakan sebuah platform yang disediakan oleh esri, dimana platform ini dapat menyimpan dan melakukan distribusi antar user yang telah mempunyai akun dalam Arcgis online. Berikut merupakan data citra yang sudah dibentuk dan di upload ke dalam file (.TPK).

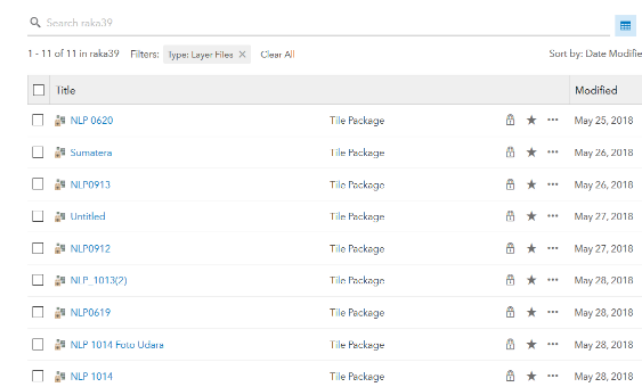

Gambar 3. Bentuk file (.TPK) setelah dilakukan uploading

Gambar diatas menunjukkan data yang telah di upload menggunakan file tile package (.TPK) dimana tile package berfugsi untuk melakukan compressing data setelah peta dibentuk tile per zooming levelnya.

\section{Tampilan Pada Image Map Service}

Untuk menampilkan data pada Image map service ini dapat dilakukan pada platform Arcgis online. Untuk melihat data-data citra yang dapat digunakan sebagai peta dasar dapat dilihat pada galeri dengan tampil seperti berikut.

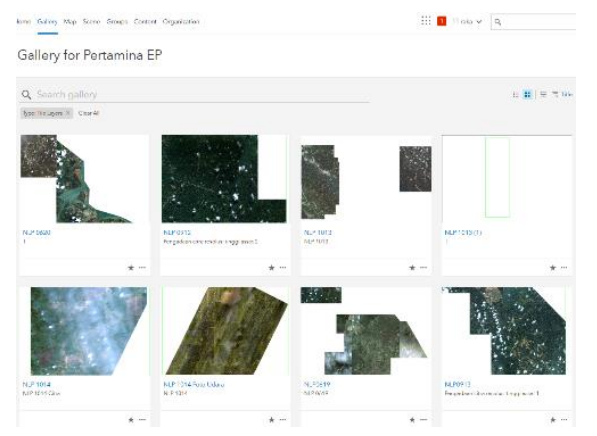

Gambar 4. Galeri Image Map Service telah dalam bentuk Tile Layer

a. Overviews

Pada halaman overviews pengguna dapat melihat informasi-informasi terkait mengenai data citra yang ada sesuai dengan indeks nomor lembar peta. Konten utama pada halaman overviews ini adalah description, title, dan summary. Tujuan dari ditambahkannya penjelasan dari data citra tersebut adalah agar pengguna mengetahui informasi seperti tahun citra dan lokasi dari pengambilan gambar citra tersebut. 


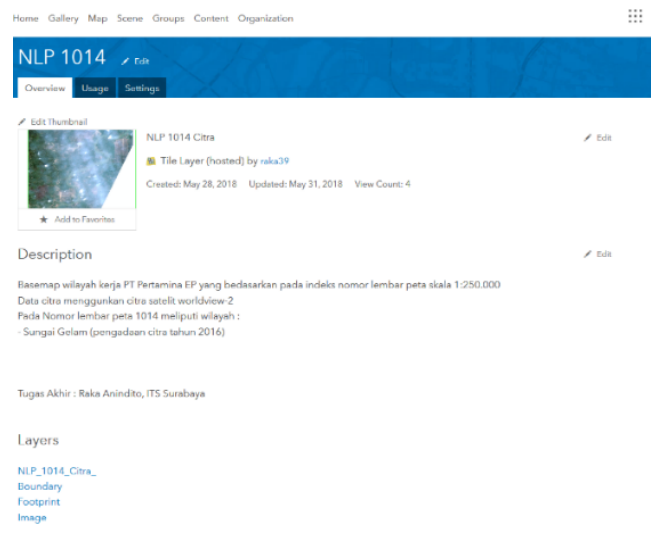

Gambar 5. Tampilan overview pada fitur ArcGIS online

b. Map Viewer

Map viewer merupakan sebuah tempat pada ArcGIS online untuk membuka maupun menggunakan data peta dasar (basemap) tersebut. Pada contohnya pengguna dapat menggunakan data tersebut untuk dijadikan peta dasar dalam pembuatan peta khusus di dalam platform ArcGIS online. Pada map viewer terdapat fitur zoom in dan zoom out. Fitur tersebut memungkinkan pengguna untuk melakukan perbesaran serta memperkecil tampilan peta.

Publisher dapat melakukan pengaturan zooming level dimana pengguna hanya dapat melakukan zoom in dan zoom out pada skala yang sudah diatur oleh publisher.

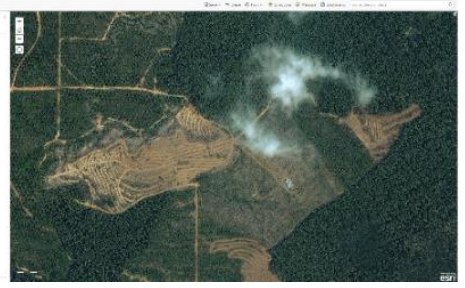

Gambar 6. Tampilan pada map viewer

Untuk memasukkan beberapa data dalam satu tampilan, pengguna dapat melakukan perintah "add" pada kolom di sebelah "details".

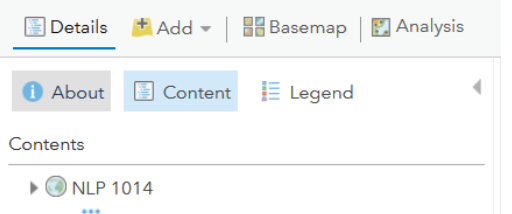

Gambar 7. Menambahkan data ke dalam map viewer

Kemudian pengguna dapat menggunakan
opsi "move to basemap" untuk
menggunakannya sebagai peta dasar.

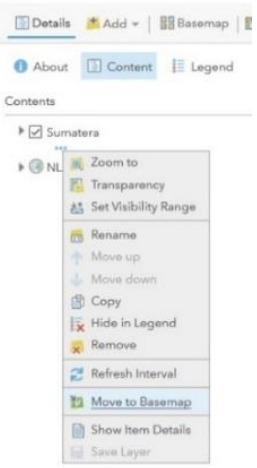

Gambar 8. Menggunakan data sebagai database

\section{Analisis Pengembangan Image Map Service}

Layanan "image map service" dengan menggunakan data raster merupakan sebuah layanan yang dibuat agar data dapat digunakan pada hardware yang berbeda dan memiliki referensi spasial yang sesuai dengan standard. Setelah layanan persebaran data raster guna kebutuhan peta dasar selesai dibuat, 2 proses yang dilakukan untuk melakukan peremajaan terhadap data yaitu alur distribusi dan updating terhadap database haruslah dibuat. Berikut adalah beberapa tahapan terkait distribusi dan updating data :

a. Distribusi

Distribusi merupakan sebuah fungsi dimana seorang "publisher" melakukan persebaran data raster yang telah dilakukan pengolahan sehingga data tersebut dapat digunakan sebagai peta dasar. Berikut merupakan alur yang dilakukan publisher dalam melakuka distribusi data:

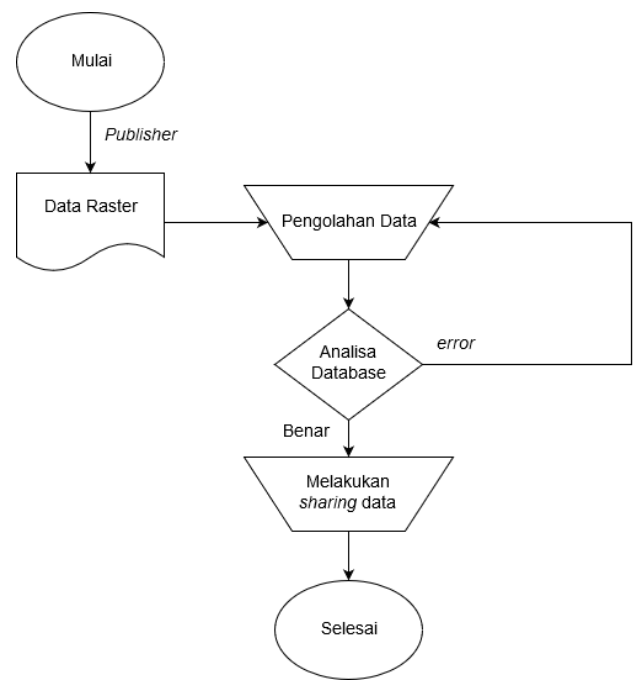

Gambar 9. Alur melakukan distribusi 
b. Updating

Pada fungsi updating "publisher" dapat melakukan pembaharuan maupun penghapusan data raster yang digunakan dalam layanan "Image Map Service" . Pada pembuatan layanan ini peta dasar dibagi bedasarkan nomor lembar peta RBI dengan skala 1:250.000, hal tersebut dapat memperingan pada proses pembaharuan pada saat memasukkan data ke dalam platform ArcGIS online. Hal tersebut dikarenakan beban data akan berkurang, sehingga mempercepat proses uploading. Beberapa syarat yang harus dilakukan pada saat updating adalah:

i. Data harus memiliki referensi spasial yang sama.

ii. Database yang sudah di update harus kembali di save pada file tile package (.TPK).

iii. Nama tile package harus sesuai dengan nama tile package pada saat dibuat.

c. Kecepatan penampilan

Kecepatan penampilan peta pada map viewer merupakan langkah dimana melakukan test terhadap response time yang diperlukan untuk membuka data peta dasar tersebut. Untuk melakukan test ini dilakukan dengan memakai aplikasi pulse yang dapat memperkirakan waktu dari response time web, berikut adalah hasil yang di dapat setelah dilakukan test sebanyak 10 kali.

Tabel 1. Response time load data

\begin{tabular}{lcc}
\hline \multicolumn{1}{c}{ Layer } & $\begin{array}{c}\text { Response } \\
\text { time (ms) } \\
\text { (mean) }\end{array}$ & $\begin{array}{c}\text { Volume } \\
\text { Data (mb) }\end{array}$ \\
\hline NLP 0619 & 728,7 & 1740 \\
\hline NLP 0620 & 804,7 & 3565 \\
\hline NLP 0912 & 698,3 & 348 \\
\hline NLP 0913 & 735 & 3283 \\
\hline NLP 1013 & 740,2 & 1453 \\
\hline NLP 1014 & 735,1 & 802 \\
\hline NLP 1014 foto udara & 769,4 & 2126 \\
\hline Sumatera & 802,7 & 1294 \\
\hline
\end{tabular}

Dari hasil tersebut dapat dilihat bahwa hasil untuk response time yang di dapat di setiap layernya tidak berbanding lurus dengan volume datanya dan cenderung stabil pada setiap layernya.

d. User-friendly

Setelah layanan terhadap penyediaan peta dasar dengan resolusi tingkat tinggi berhasil di upload ke dalam ArcGIS online kemudian dilakukan test apakah layanan penyediaan peta dasar dengan menggunakan data citra worldview-2 dan orthofoto tergolong ke dalam user-friendly dengan menggunakan parameter-parameter oleh kay singh sebagai berikut.

Tabel 2. Persyaratan user-friendly

\begin{tabular}{ccc}
\hline NO & Komponen persyaratan & Keterangan \\
\hline 1 & Dapat dibuka pada handphone & Tidak Berfungsi \\
\hline 2 & Dapat digunakan oleh seluruh pengguna & Dapat digunakan \\
\hline 3 & Memiliki arsitektur yang baik & Baik \\
\hline 4 & Pengadaan informasi & Baik \\
\hline 5 & Waktu load yang cepat & Baik \\
\hline 6 & Dapat digunakan pada browser berbeda & Dapat digunakan \\
\hline 7 & Penggunaan navigasi & Baik \\
\hline
\end{tabular}

e. User-consumption

Pengguna dari Image Map Service pada penelitian kali ini adalah dengan batasan user hanya pada kalangan karyawan PT Pertamina EP yang memiliki akun pada ArcGIS online yang dapat mengaksesnya. Bedasarkan hasil survei yang dilaksanakan pembuatan Image Map Service dalam menampilkan peta dasar dengan bentuk data raster berguna dalam pembuatan peta berbasis online guna fungsi monitoring maupun pelaporan evaluasi. Selain itu dari segi teknologi, pembuatan Image Map Service berguna agar dapat digunakan pada seluruh kantor cabang.

\section{Analisa Beban Data}

Analisa Beban data bertujuan untuk membandingkan antara volume data awal dan akhir. Berikut merupakan beban data awal dan akhir: 
a. Data citra resolusi tinggi

Tabel 3. Beban Data Citra Resolusi Tinggi

\begin{tabular}{lc|cc}
\hline \multicolumn{2}{c|}{ Tile disk space } & \multicolumn{2}{c}{ Raw Disk space } \\
\hline Layer & $\begin{array}{c}\text { Beban } \\
\text { data } \\
\text { (MB) }\end{array}$ & Layer & $\begin{array}{c}\text { Beban } \\
\text { data }\end{array}$ \\
\hline NLP 0619 & 1740 & & \\
NLP 0620 & 3565 & & \\
NLP 0912 & 348 & NLP 0619, & 328,720 \\
NLP 0913 & 3283 & NLP 0620, & GB \\
NLP 1013 & 1453 & NLP 0912, & \\
NLP 1013 (1) & 548 & NLP 0913, & \\
NLP 1014 & 802 & NLP 1013, & \\
NLP 1014 Foto udara & 2126 & & \\
\hline & 9,172 & To14 & GB \\
Total & GB & Total \\
\hline
\end{tabular}

b. Data citra resolusi rendah

Tabel 4. Beban Data Citra Resolusi Rendah

\begin{tabular}{|c|c|c|c|}
\hline \multicolumn{2}{|c|}{ Tile disk space } & \multicolumn{2}{|c|}{ Raw Disk space } \\
\hline Layer & $\begin{array}{c}\text { Beban } \\
\text { data } \\
\text { (MB) }\end{array}$ & Layer & $\begin{array}{c}\text { Beban } \\
\text { data } \\
\text { (MB) }\end{array}$ \\
\hline Sumatera & 1294 & Sumatera & 315 \\
\hline & 1,294 & & 315 \\
\hline Total & $\mathrm{GB}$ & Total & MB \\
\hline
\end{tabular}

Pada hasil tersebut di dapatkan bahwa beban data akhir yang dihasilkan lebih rendah, hal tersebut disebabkan karena perubahan format dari data awal (.TIFF) menjadi mixed namun pada citra resolusi rendah terjadi peningkatan beban data yang disebabkan karena pada awal pemakaian citra tersebut ber format Enhanced Compression Wavelet (.ecw). Pada penelitian kali ini, digunakan format data mixed yang menggambarkan peta dengan menggunakan format JPEG pada tengah gambar peta dan PNG32 pada sisi luar peta dimana format ini menggambarkan data lebih baik, mendukung untuk layer transparant dan lebih hemat penyimpanan data dibanding harus menggunakan format PNG32. Dimana akan mengurangi pengeluaran untuk penyimpanan data tersebut.

Selain pada format data, pengaruh dari setiap level zooming akan meningkatkan beban data dari layer tersebut. Semakin tinggi skala yang ditentukan maka akan semakin banyak tile yang terbuat, sehingga berpengaruh pada beban data.

\section{KESIMPULAN}

Dalam pembuatan Image Map Service ini dapat disimpulkan bahwa:

1. Setelah dilakukan uji coba Image Map Service, data raster tersebut dapat terintegrasi pada hardware yang berbeda dengan baik. Dengan sifat data yang rahasia, sistem Image Map Service dengan tujuan untuk dapat digunakan sebagai peta dasar dalam pembuatan peta pada lingkup kerja PT Pertamina EP sehingga pada implementasinya hanya pengguna yang sudah dalam lingkup tersebut yang dapat menggunakannya.

2. Beban data yang dihasilkan pada pembuatan tile tergantung dari skala zooming yang akan dihasilkan. Hal tersebut dikarenakan, semakin tinggi tingkat skala yang dibuat maka total tile akan semakin banyak sehingga beban data yang dihasilkan akan semakin besar.

3. Image Map Service dengan tujuan melakukan pemanggilan data dalam bentuk data raster untuk kebutuhan penggunaan sebagai basemap denga basis online dapat berfungsi dengan baik dan mudah. secara sistem dapat tergolong kedalam user-friendly dan telah memenuhi kebutuhan dari pengguna.

4. Penggunaan sistem Image Map Service menggantikan sistem pemakaian data raster lama secara analog menggunakan basis online. Hal tersebut dapat membuat penggunaan data raster sebagai peta dasar dapat dibuka di seluruh workstation PT Pertamina EP dan pada seluruh branch kantornya.

5. Response time yang dihasilkan pada pembukaan web pada setiap layer dihasilkan dengan rata-rata waktu 601,4 ms. dengan rata-rata waktu tercepat $698,3 \mathrm{~ms}$ pada layer NLP 0912 dan waktu terlama 804,7 ms pada layer 0620.

\section{UCAPAN TERIMA KASIH}

Penulis mengucapkan terima kasih kepada Bapak Dr-Ing. Ir. Teguh Hariyanto, M.Sc, selaku dosen pembimbing 1 serta kepada Bapak Sondy Hardian Meisajiwa S.T dan seluruh rekan PT Pertamina EP yang telah turut banyak membantu dalam penulis 
melakukan penelitian ini sehingga penelitian ini dapat berjalan dengan lancar.

\section{DAFTAR PUSTAKA}

Bank Indonesia. 2017. Laporan Tahunan: Annual Report 2016. Bank Indonesia.

Dewi, Esthi Kurnia. 2015. Optimalisasi Web GIS dengan Metode Tiling. ISBN: 979-26-0280-1: SM102.

Esri. 2014. ArcGIS Online: The Mapping Platform for Your Organization. New York: Esri.

Garca, Ricardo et al. 2012. "Web Map Tile Services for Spatial Data Infrastructures: Management and Optimization." Cartography - A Tool for Spatial Analysis.

Schwartz, Joe. 2006. Bing Maps Tile System.

Singh, Kay. 2013. Web Design: 11 Characteristics of a user-friendly website.

Yang, Chaowei, dkk. 2011 .WebGIS performance issues and solutions. Advances in Web-based GIS. Mapping Services and Applications - Li, Dragic evic \& Veenendaal. Li ISPRS: 121-138. 2011. 